\title{
Heat Transfer on Accreting Ice Surfaces
}

\author{
Keiko Yamaguchi* and R. John Hansman Jr.† \\ Massachusetts Institute of Technology, Cambridge, Massachusetts 02139
}

\begin{abstract}
Based on previous observations of glaze Ice accretion on aircraft surfaces, a multizone model with distinct zones of different surface roughness is demonstrated. The use of surface roughness in the LEWICE Ice accretion prediction code is examined. It was found that roughness is used in two ways: 1) to determine the laminar to turbulent boundary-layer transition location and 2) to calculate the convective turbulent heat-transfer coefriclent. A two-zone version of the multixone model is implemented in the LEWICE code, and compared with experimental convective heat-transfer coeficient and lce accretion results. The analysis of the boundary-layer transition, surface roughness, and viscous flowfield effects significantly increased the accuracy in predicting heat-transfer coeficients. The multizone model was found to significantly improve the ice accretion prediction for the cases compared.
\end{abstract}

\section{Introduction}

\begin{abstract}
A. Background
I rime ice accretion, which occurs at cold temperatures, there is adequate convective heat transfer to rapidly freeze the impinging supercooled water droplets. The rapid freezing results in an opaque white ice due to entrapped air bubbles. Because of the rapid freezing, rime ice shapes are determined solely by the droplet impingement behavior; efforts to model rime ice accretion have been relatively successful.

In contrast, current efforts to analytically model glaze ice accretion are hampered by insufficient knowledge of the accreting ice surface roughness. In glaze icing, which normally occurs at temperatures near freezing or at high liquid water contents, there is insufficient convective heat transfer to remove all of the latent heat of freezing from the impinging supercooled water droplets. The water freezes slowly, resulting in a strong clear ice structure. The local ice accretion rate is controlled by the ability to remove latent heat and thus the local convective heat transfer. The droplet impingement behavior also plays an important role in determining where on the surface there is sufficient impingement that the surface is wet.

The local convective heat transfer from a surface is known to be strongly dependent on the ice surface roughness.' $\mathrm{Be}$ cause of the importance of heat transfer on the ice accretion rate, surface roughness becomes an important factor in modeling glaze ice accretion. Current analytical models such as LEWICE generally assume that the surface roughness is uniform and the effective sand grain roughness $k_{3}$ is used as an input parameter in the code. ${ }^{2.3}$ The magnitude of $k_{a}$, the roughness parameter, is normally determined empirically by comparison of predicted and experimental ice accretions. The erratic performance of glaze ice accretion models and the empirical manner in which the surface roughness is treated indicate the need for a more deterministic treatment of the surface roughness.
\end{abstract}

\section{B. Multizone Model}

In prior experiments, detailed observations of accreting ice surface roughness were made at several icing facilities. ${ }^{4-6}$ As

Presented as Paper 90-0200 at the AIAA 28th Acrospace Sciences Meeting, Reno, NV. Jan. 8-11, 1990; received April 6, 1990; revision received Feb. 15, 1991; accepted for publication March 5, 1991 Copyright (c) 1990 by M.I.T. Published by the American Institute of Aeronautics and Astronautics, Inc. with permission.

-Research Assistant. Student Member AIAA.

tAssociate Professor. Associate Fellow AlAA. a result of the detailed photographic analysis of accreting ice surfaces in these facilities, distinct regions were identified each having a characteristic roughness and identifiable boundaries. Based on these observations, a multizone model, in which the accreting ice surface is divided into two or more discrete zones with varying surface roughness and water behavior, was proposed.

\section{Surface Roughmess Zones}

A total of three roughness zones were identified. A typical ice accretion showing the three zones is shown in Fig. 1.

1) Smooth zone: Close to the stagnation point, the surface was observed to be uniformly wet with a thin film of water at warm temperatures. In this "smooth zone," the surface was smooth with no distinctively visible roughness.

2) Rough zone: At some point downstream, there was a sudden transition to a significantly rougher zone, where there appeared to be insufficient water to maintain a uniform film, and the water tended to coalesce into the water beads first observed by Olsen and Walker. ${ }^{7.8}$ In this "rough zone," the ice accretion rate was observed to be enhanced compared to the smooth zone. This is thought to be due to increased heat transfer resulting from the greater surface roughness.

In certain glaze ice accretions, particularly at high liquid water contents, some of the roughness elements within all or part of the rough zone were observed to grow into distinct protuberances. With higher collection efficiency and enhanced heat transfer, these protuberances tended to grow rapidly resulting in horned ice accretions.

3) Runback or rime feather zone: Behind the impingement region, aft of the rough zone, ice was observed to accrete by two different processes, depending on temperature. At warm temperatures, a runback zone was observed aft of the rough zone, which was characterized by areas of ice interspersed with un-iced surface. The surface water was observed to initially runback and then stagnate at the point of flow separation, where this water slowly froze as rivulets or as large coalesced water cells. At cold temperatures, rime feathers were sometimes observed to grow in the region aft of the primary accretion. The feathers were dry ice accretions, which propagated in the local upstream direction.

\section{Roughness Transition Location}

The angular position of the boundary between the smooth and rough zones has been experimentally observed as a function of time for cylinders. A typical example is shown in Fig. 2 for a $1 \mathrm{in}$. diameter cylinder. This data was obtained using the technique discussed in Sec. IVA. The initial location of roughness transition is believed to be caused by, and to coincide with, the location of the boundary-layer transition from

Supported by government grant. See Acknowledgments. 


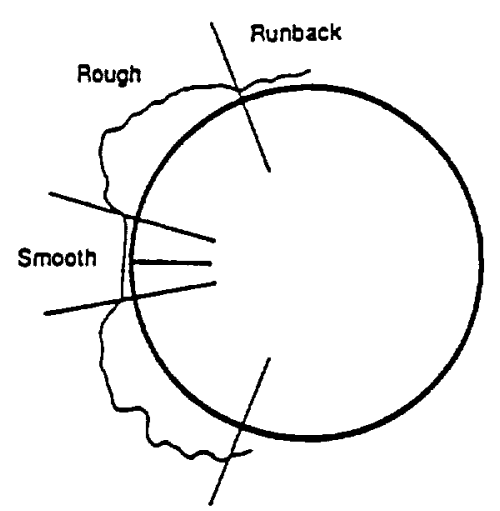

Fig. 1 Typlcal glaze ice shape for a 2-min exposure on a 1-in. cylinder showing the three distinct roughness zones $\left(T=-4.5^{\circ} \mathrm{C}, V=150\right.$ $\mathrm{kt}$, liquid water content $=1.0 \mathrm{~g} / \mathrm{m}^{3}$, and median volumetric diameter $=\mathbf{3 0} \mu \mathrm{m}$ )

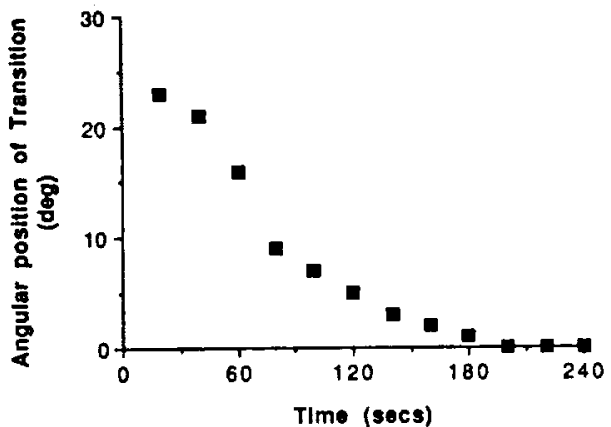

Fig. 2 The angular position vs time of smooth-rough transition locatton $\left(T=-7^{\circ} \mathrm{C}, V=125 \mathrm{kt}\right.$, liquid water content $=0.8 \mathrm{~g} / \mathrm{m}^{3}$, and median volumetric diameter $=12 \mu \mathrm{m}$ ).

laminar to turbulent. Experimentally, the rough/smooth transition was observed to propagate with time towards the stagnation region for a wide variety of icing conditions. The effect of icing cloud parameters on the transition location has been studied in an attempt to identify the underlying physical mechanisms that cause the rough surface to develop. It was found that higher velocity tends to move the initial location of the transition closer to the stagnation point. Warmer temperatures and higher liquid water contents tend to move the transition point more quickly towards the stagnation region.

Observations that the smooth/rough transition depends on Reynolds number indicate that the initial transition in surface roughness is caused by boundary-layer transition. In these cases, the laminar/turbulent boundary-layer transition point will also be the initial smooth/rough transition point. In the laminar region, the heat transfer is low enough that all of the latent heat cannot be removed and the surface is coated by a uniform water film. However, the enhanced heat transfer in the turbulent region can cause sufficient freezing to partially dry the surface and cause bead formation, which results in the increased roughness and the increased heat transfer observed in the rough region.

The influence of surface water flow on the smooth/rough transition location also indicates that dynamic effects are important. It is thought that the dynamic effects are caused by bead formation at the interface between the smooth and rough surface zones as shown in Fig. 3. The formation of these beads at the interface causes enhanced heat transfer within the rough zone, which tends to freeze out the downstream beads and dry the surface. As the surface dries, beads begin to form further upstream and the transition point will propagate towards the stagnation region as observed experimentally. As

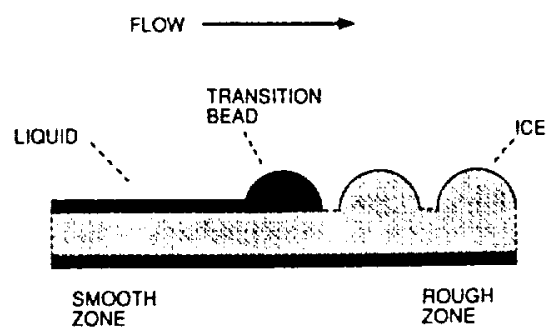

Fig. 3 Schematic representation of bead formation at the smooth-torough Iransition.

roughness moves upstream, the boundary layer is tripped and will move with the roughness transition. By increasing the surface water flux, the rate of formation and growth of the interfacial beads is increased. This causes the observed faster upstream propagation of the transition point with increased surface water flux.

Based on the experimental observation of the smooth/rough transition location, it was determined that for some cases, the initial smooth/rough transition occurs on the laminar/turbulent boundary-layer transition point. Therefore, for the purposes of ice accretion prediction, it is hypothesized that the smooth/rough transition location can be assumed to coincide with the laminar/turbulent boundary-layer transition.

\section{Model Description}

In contrast to the conventional techniques that assume uniform roughness over the entire ice accretion, the multizone model is divided into two or more discrete zones with varying surface roughness and surface water behavior to be consistent with experimental observations.

In the simplest version of the model, the surface is divided into two zones, the "smooth" zone and the "rough" zone. In the "smooth" zone, corresponding to the smooth region centered about the stagnation line, the surface is uniformly wet, with thin water film runback. The heat transfer is that for a laminar boundary layer and a Messinger ${ }^{9}$ type water runback model used in the original LEWICE code appears to be valid.

In the "rough" zone, surface tension effects are important and the characteristic water beads or roughness elements appear. Here, the heat transfer is enhanced due to increased roughness and the experimental results have indicated no water runback in this region for some cases. ${ }^{3-8}$

\section{Implementing the Multizone Model Through Boundary-Layer Transition}

Based on the hypothesis that the smooth/rough transition location coincides with the laminar/turbulent boundary-layer transition, a simple more physically realistic multizone model was implemented in the LEWICE code. Basically, the smooth and rough zones were considered to coincide with the regions of laminar and turbulent boundary layer, which are treated separately when calculating heat transfer in LEWICE. In order to implement the multizone model effectively, the use of surface roughness in the LEWICE code was examined. The multizone model was then implemented in the LEWICE code through boundary-layer transition in order to evaluate the effectiveness of the model.

A. Use of Roughness in LEWICE

In the original LEWICE code, the only roughness parameter is the equivalent sand grain roughness height $k_{s}$. This parameter, which is one of the most important factors in determining the ice shape, ${ }^{7.8}$ is used in two ways. One use is to determine the location of boundary-layer transition from laminar to turbulent, and the other is to calculate the magnitude of heat transfer in the turbulent region.

The boundary-layer transition is determined in the laminar region with reference to a critical Reynolds number based on 


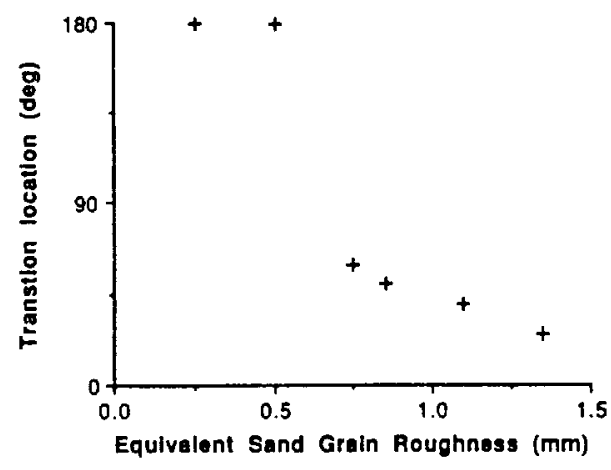

Fig. 4 Effect of $k$, in the laminar region on the transition location.

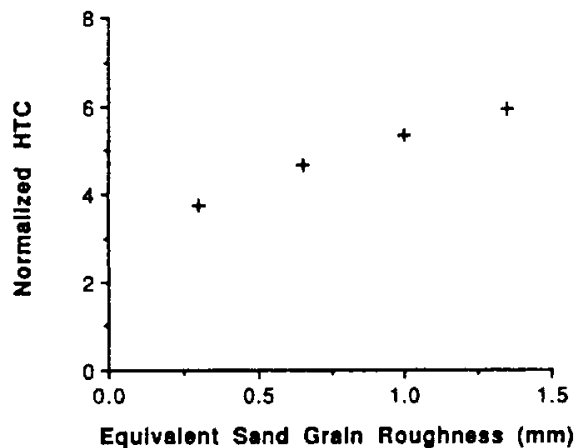

Fig. 5 Effect of $k$, in the turbulent region on the magnitude of the heat-transfer coeficient (Note: Normalized HTC $=H T C / \sqrt{N u}$ ).

the roughness element height and local velocity. This Reynolds number is

$$
R e_{1}=\frac{k_{s} v_{k}}{\nu}
$$

where $k$, is the roughness element height in the laminar region, $v_{k}$ is the air velocity at distance $k$, from the surface, and $\nu$ is the kinematic viscosity of the air. When this local Reynolds number exceeds a critical value of 600 , the boundary layer is transitioned to turbulent, ${ }^{10}$ and any region downstream of this point is considered to have turbulent boundary layer. The effect of varying $k$, in this region on the transition location is demonstrated in Fig. 4 by running LEWICE on a $0.15-\mathrm{m}$ diam cylinder at a velocity of $25 \mathrm{~m} / \mathrm{s}$ and temperature of $0^{\circ} \mathrm{C}$. It is noted that no transition occurs until a value of $k_{s}$ above $0.5 \mathrm{~mm}$. At higher values, the transition location propagated towards the stagnation region with increasing $k_{1}$.

In the laminar region, the heat transfer is independent of the roughness element height, assuming the roughness height is less than the boundary-layer thickness. In regions with a turbulent boundary layer, the roughness element height is used in another way. Here, roughness plays an important role in the heat transfer. Calculation of the heat-transfer coefficient in the turbulent region involves a complicated set of equations based on flow parameters, roughness, and the geometry of the accreting body, including the roughness element height. ${ }^{3}$ Because of the complexity of these equations, it is very difficult to determine the effects of the equivalent sand grain roughness $k$, on the turbulent heat transfer analytically. However, these effects of $k$, on heat transfer were observed numerically using the LEWICE code. An example is shown in Fig. 5 where the convective heat-transfer coefficient (HTC) normalized by the square root of the Nussult number (i.e., normalized $H T C=H T C / \sqrt{N u}$ ) is plotted against $k_{s}$, for a 0.15 -m-diam cylinder at a velocity of $33 \mathrm{~m} / \mathrm{s}$ and temperature of $0^{\circ} \mathrm{C}$. It was found that increasing $k_{s}$ significantly increased the heat transfer in the turbulent region.

Because of the manner in which roughness is treated in the LEWICE code, it is possible to separate the surface roughness in the laminar and turbulent regions. The laminar roughness value is then used to determine the laminar to turbulent boundary-layer transition location. The turbulent roughness is used to calculate the heat-transfer coefficient in the turbulent region.

\section{B. Implementalion of the Multizone Model}

In order to evaluate the effectiveness of the multizone model, a simple two-zone version was implemented in the LEWICE code. For the first time step, different roughness are used for the laminar and the turbulent regions. In subsequent time steps, the boundary-layer transition point is made to propagate towards the stagnation line in a manner consistent with experimental observations of the smooth/rough transition. In order to avoid errors due to improper boundary-layer transition placement in these initial evaluations, the transition location was input to the code from the experimental measurements of smooth/rough transition migration such as those shown in Fig. 2. It should be noted that a deterministic prediction of the smooth/rough transition migration valid for all geometries and based on nominal code inputs is necessary for a full implementation of the multizone model.

For the initial time step, the user can input two different roughness element sizes, one for the laminar region $k_{1}$ and another for the turbulent region $k_{r}$. As explained in Sec. IIB, the roughness element height is used in LEWICE for different purposes in the two regions. By separating the two, it is possible to control the transition location and the turbulent heat transfer independently. This method more closely emulates the physical situation where two different roughness element heights have been observed in the smooth and rough regions. In the laminar region, a roughness height $k_{l}$ corresponds to the roughness of the uniform water film found in the experimental observations. In the turbulent region, the roughness height $k$, corresponds to the roughness size observed in the rough zone. This method is valid only for the first time step where the transition location is determined mainly from the boundary-layer instability and the dynamic effects of surface water are negligible.

For subsequent time steps, the angular locations of the laminar to turbulent transition point as a function of time are specified based on the experimental data. The roughness element height $k$, for the turbulent region still needs to be specified. For some cases, however, the experimental results have indicated that freezing fraction is unity (i.e., all impinging water freezes) in this region. For these cases, the ice shape is not dependent on the roughness element height that user chooses, since $k_{r}$ is large enough to ensure that there is enough heat transfer to remove all of the latent heat.

\section{Ice Shape Comparisons on Cylinders}

\section{A. Comparison with Original LEWICE}

In order to investigate the discrepancy that had been observed between the experimentally observed roughness element sizes and the recommended roughness element size in LEWICE," several original LEWICE runs were compared to the experimental heat-transfer coefficient data of Achenbach for rough 0.15 -m-diam cylinders.' The measurements provide convective heat transfer coefficient data for cylinders with known surface roughness sizes at various Reynolds numbers. In the following figures, $\theta$ indicates the angular position along the cylinder, where 0 deg is the stagnation point. The vertical axis indicates the heat transfer coefficients normalized by the square root of the Nussult number.

A typical heat transfer comparison is shown in Fig. 6 for a case with $R e=1.27 \times 10^{3}$ and a moderate roughness element 


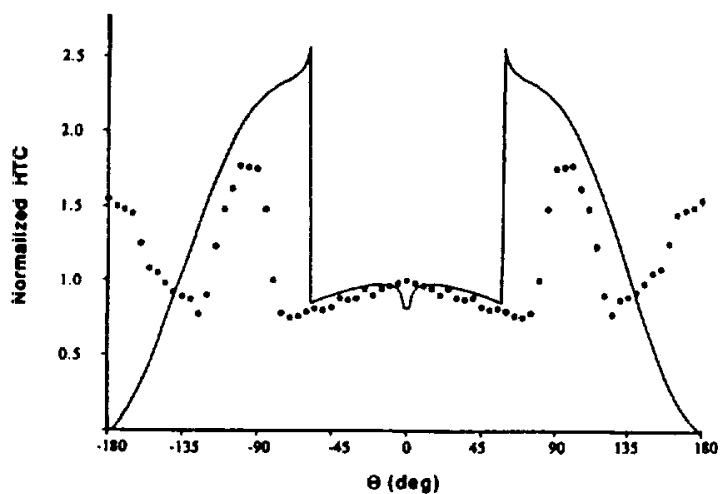

Fig. 6 LEWICE predicted and Achenbach measured heat-transfer coefficients for a cylinder with equivalent sand grain roughness $k_{k}=$ $0.115 \mathrm{~mm}$ and $R e=5.9 \times 10^{5}$ (Note: Normalized $H T C=$ $H T C / \sqrt{N u}$.

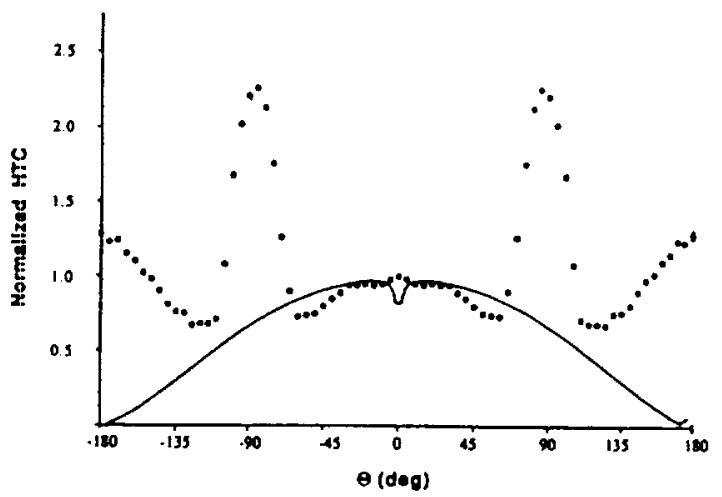

Fig. 7 LEWICE predicted and Achenbach measured heat-(ransfer coeficients for a cylinder with equivalent sand grain roughness $k_{1}=$ $0.45 \mathrm{~mm}$ and $R e=1.27 \times 10^{5}$ (Note: Normalized $H T C=$ $\mathrm{HTC} / \sqrt{\mathrm{Nu}}$ ).

size $k_{s}$ of $0.45 \mathrm{~mm}$. In this case, the heat transfer is wellpredicted in the laminar region. However, where the transition to a turbulent boundary layer is indicated by a rise in the Achenbach heat transfer data at 75 deg. LEWICE predicts transition further forward at $57 \mathrm{deg}$. This discrepancy can be explained by one of the following hypotheses. One is that the roughness eloment height $k$, used to calculate the critical transition Reynolds number is not correct. The other is that the transition model, based on the critical roughness element Reynolds number of 600 , is not valid for this case.

The comparisons shown in Fig. 6 also indicate a difference in the magnitude of heat transfer predicted in the turbulent region. LEWICE can be seen to clearly overpredict the heat transfer in this region. This result indicates the need to further investigate the effect of roughness on heat transfer in the turbulent region.

Another comparison is shown in Fig. 7 for a case with $R e$ $=5.9 \times 10^{5}$ and a small roughness element height $k$, of 0.115 $\mathrm{mm}$. Here, LEWICE does not predict transition at all, where the experimental result indicates a transition at $63 \mathrm{deg}$. For this case of very small roughness element size, the transition model is clearly not valid, since it fails to predict transition at all, indicating a limit of the critical transition Reynolds number theory.

\section{B. Effect of External Flowneld Model}

Because the local convective heat transfer coefficient is strongly dependent on the external flow velocity on the sur-

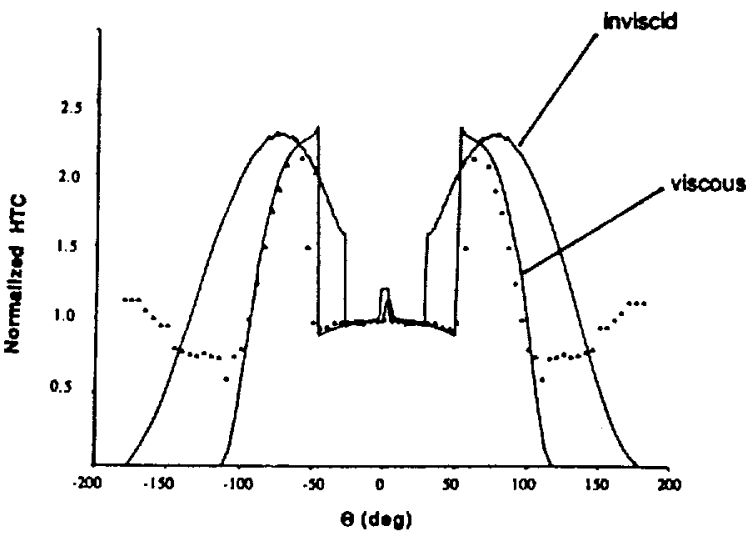

Fig. 8 A comparison of normalized heat-transfer coemcients calcu. lated viscous and inviscld flowfields $\left(R e=7.3 \times 10^{4}\right.$ and $k_{0}=1.35$ mm).

face, errors in the velocity field will manifest as errors in the convective heat transfer coefficient. This can be seen in Fig. 6. Because LEWICE uses an inviscid flow model, it cannot accurately calculate the flowfield in the separation region behind the cylinder. This is thought to be the cause of the large discrepancy between LEWICE and the experimental results in Fig. 6 for angles greater than 135 deg.

The inability of LEWICE to accurately calculate heat transfer in separation and recirculation zones may be significant for glaze ice modeling where such regions are common behind "horn-shaped" ice accretions. It should be noted, however, that there is very little droplet impingement in the recirculation regions and that the heat transfer discrepancies will be most apparent in ice accretions where there is surface water runback into the recirculation region.

In order to verify that it is possible to predict heat transfer more accurately using the LEWICE methodology with a more accurate velocity field, the potential flowfield was replaced with a well-documented empirical formula for cylinders." The heat transfer was calculated using the empirical flowfield and an example is shown in Fig. 8. In this comparison, the critical Reynolds number was set at 975 to match the boundary-layer transition location based on the known roughness element height of $1.35 \mathrm{~mm}$. It can be seen that the heat-transfer prediction was significantly improved by the use of the viscous flowfield and a more accurate prediction of boundary-layer transition location.

\section{Comparison with Experimental Ice Accretion Data}

\section{A. Experimental Setup}

In order to obtain roughness transition locations as a function of time on well-defined ice shapes for comparison with the multizone model, detailed observations of accreting ice shapes on cylinders at various cloud conditions were made at the B. F. Goodrich Ice Protection Research Tunnel. A series of 1-in.-diam cylinders were observed at a freestream velocity of $125 \mathrm{kt}$. The liquid water content (LWC) ranged from $0.4-$ $1.5 \mathrm{~g} / \mathrm{m}^{3}$ with median volumetric diameter (MVD) of $11-40$ $\mu \mathrm{m}$. The tunnel total air temperatures varied from $0^{\circ} \mathrm{C}$ to $-15^{\circ} \mathrm{C}$.

The photographic setup used in the tunnel is shown in Fig. 9. The cylinders horizontally spanned the test section. The test section walls had heated glass windows to provide photographic access. Two charge-coupled device (CCD) highmagnification microvideo cameras were used to obtain a graz- 


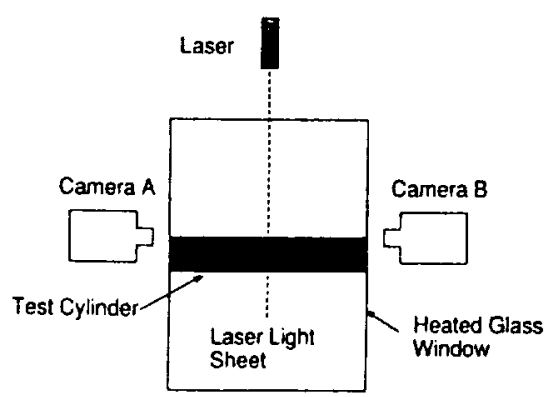

Fig. 9 Schematic diagram of the photographic setup in the icing wind tunnel.

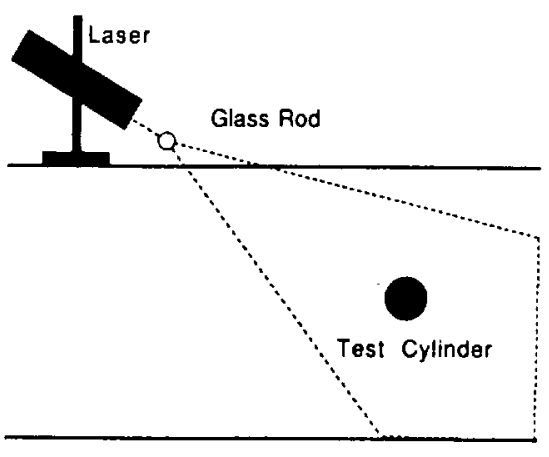

Tunnel Wall

Fig. 10 Schematic diagram of the fan laser beam setup in the icing wind tunnel.

ing angle view of the ice accretion. The cameras were focused at the central region of the tunnel where the cloud was most uniform.

A laser light sheet was used to illuminate a plane perpendicular to the test cylinders to accurately identify the plane of focus (Fig. 10). With the laser sheet, it was possible to record on video and still cameras the details of accreting ice shapes and roughness at a single spanwise location. Because the rougher surface in the rough region increased the internal reflection, the ice shape appeared brighter in the rough region, which allowed an accurate identification of smooth to rough transition point. The external light inside the tunnel was turned off at a specific time interval, usually $20 \mathrm{~s}$, providing enhanced details in the laser illuminated ice shape.

\section{B. Comparison of Actual and Predicted Ice Shapes}

An example of actual and predicted ice shapes using the multizone LEWICE code and the original LEWICE code values for a 4-min ice accretion at 20-s intervals is shown in Fig. 11. The icing cloud condition was $-7^{\circ} \mathrm{C}, 125 \mathrm{kt}$, LWC of $0.8 \mathrm{~g} / \mathrm{m}^{3}$, and a MVD of $12 \mu \mathrm{m}$. The angular position of transition was measured from the video recordings at 20-s intervals and is shown in Fig. 2. Characteristically, the transition was observed to migrate towards the stagnation region with time. For the original LEWICE case which used a recommended ${ }^{3}$ roughness height value of $0.04 \mathrm{~mm}$, a relatively thin conformal ice accretion was predicted. However, for the multizone case, the smooth and rough ice accretion zones significantly improved the prediction of the overall ice shape, showing a good correlation between the experimental ice accretion and predicted ice accretion using the multizone version of LEWICE. Although additional validation cases must be run, the initial improvement of the multizone prediction is encouraging.

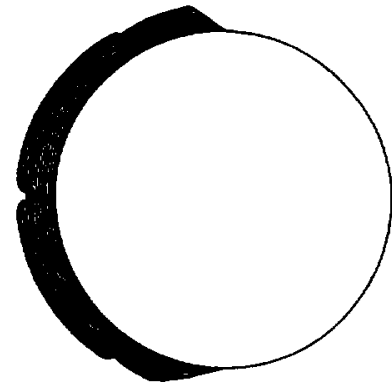

a) Original LEWICE prediction

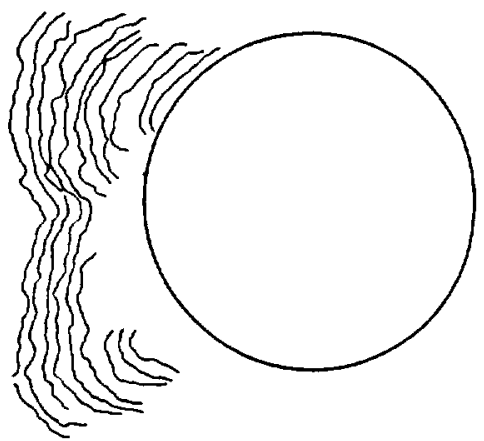

b) Experimental Ice shape

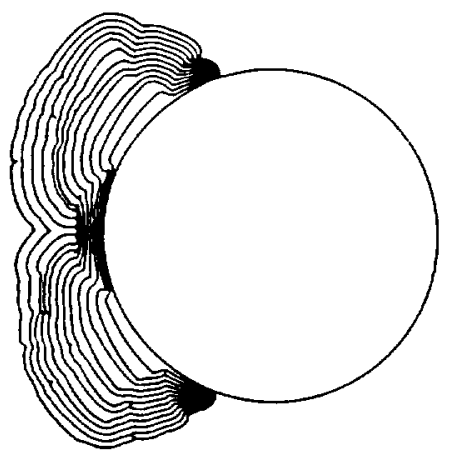

c) Multizone LEWICE prediction

Fig. 11 Comparison of origlnal and multizone LEWICE predictions with the experimental lce shapes for a $1-$ In. cylinder at 20-s intervals $\left(T=-7, V=125 \mathrm{kt}\right.$, liquid water content $=0.8 \mathrm{~g} / \mathrm{m}^{3}$, and median volumetric diameter $=12 \mathrm{\mu m}$ ).

\section{Conclusions}

The investigation of the heat transfer on accreting ice surfaces has resulted in the following conclusions:

1) The use of roughness element height in LEWICE has been investigated. The roughness influences the location of the laminar to turbulent boundary-layer transition and the convective heat transfer in the turbulent boundary-layer region. The convective heat transfer in the laminar region is independent of the roughness element height.

2) Increasing the roughness height in the laminar region was observed to move the laminar to turbulent boundarylayer transition location closer to the stagnation region. Increasing the roughness height in the turbulent region increased the turbulent heat transfer.

3) The heat transfer predicted by the multi-zone version of LEWICE was compared with known data on cylinders. It was found that by using a viscous flowfield and appropriate 
boundary-layer transition criteria, it was possible to predict the heat transfer quite accurately. This indicated the importance of having a viscous flowfield model in regions of separation and recirculation.

4) A laser fan beam technique was used to obtain highresolution profiles of ice accretions and to highlight the smoothto-rough surface transition location. This technique significantly improved the ease and accuracy of ice accretion photography.

5) An initial multi-zone version of the multizone model was implemented in the LEWICE ice accretion prediction code. For the first time step, different roughness heights for laminar and turbulent regions were used. For the subsequent time steps, an experimentally observed smooth-to-rough transition location was used to impose laminar to turbulent boundary-layer transition. The experimental observations were used to verify the concept of the multizone model. The multizone model significantly improved the prediction of the glaze ice accretion. However, further work is required to validate the approach and to develop a deterministic prediction of the rough-to-smooth transition dynamics.

\section{Acknowledgments}

This work was supported in part by the National Aeronautics and Space Administration and the Federal Aviation Administration under Grants NAG-3-666 and NGL-22-009640 . The work was also supported by the National Science Foundation Presidential Young Investigators Program, Award No. 8552702 . Use of the icing wind-tunnel facilities were provided courtesy of B. F. Goodrich De-Icing Systems.

\section{References}

'Achenbach, E., "The Effect of Surface Roughness on the Heat Transfer from a Circular Cylinder to the Cross Flow of Air," International Journal of Heat and Mass Transfer, Vol. 20, 1977, pp. 359369.

${ }^{2}$ MacArthur, C. D. "Numerical Simulation of Airfoil Ice Accretion," AlAA Paper 83-0112, Reno, NV, Jan. 1983.

'Ruff, G. A., and Berkowitz, B., "User's Manual for the NASA Lewis Ice Accretion Prediction Code (LEWICE)," NASA-CR-185129. May 1990.

'Hansman, R. J., Yamaguchi, K., Berkowitz, B., and Potapezuk, M. "Modeling of Surface Roughness Effects on Glaze Ice Accretion," AIAA Paper 89-0734, Reno, NV, Jan. 1989.

${ }^{3}$ Hansman, R. J., and Turnock, S., "Investigation of Surface Water Behavior During Glaze Ice Accretion," AIAA Paper 88-0115, Reno, NV, Jan. 1988.

'Hansman, R. J., and Turnock, S., "Investigation of Microphysical Factors Which Influence Surface Roughness During Glaze Ice Accretion." Proceedings of the 4th International Workshop on the Atmospheric Icing of Structures, Academie National de l'Aires l'Espace, Touloose, FR, Sept. 1988.

'Olsen, W., and Walker, E., "Close-Up Motion Pictures of the Icing Process." NASA Lewis Research Center Film, 1983.

"Olsen, W. A., and Walker, E., "Experimental Evidence for Mod. ifying the Current Physical Model for Ice Accretion on Aircraft Structures," NASA TM 87184, 1987.

Messinger, B. L., "Equilibrium Temperature of an Unheated Icing Surface as a Function of Airspeed," Journal of the Aeronautical Sciences, Jan. 1953, pp. 24-42.

${ }^{10}$ von Doenhoff, A. E., and Horton, E. A., "A Low-Speed Experimental Investigation of the Effect of Sandpaper Type of Roughness on Boundary-Layer Transition," NACA TN 3858, 1956.

"Zukauskas, A., and Ziugzda, J., Heat Transfer of a Cylinder in Crossflow, Hemisphere Publishing Corporation, Washington, DC, 1985. 